\title{
CHRONIC COMPARTMENT SYNDROME OF BOTH FEET
}

\author{
F. LOKIEC, I. SIEV-NER, M. PRITSCH
}

We present a case of chronic compartment syndrome of both feet in a professional ballet dancer. Intracompartmental pressure measurements established the diagnosis, decompressive fasciotomy relieved the symptoms, and the patient returned to dancing.

Case report. An 18-year-old male ballet dancer complained of pain in both feet of six months duration. The pain appeared after 10 minutes of warm-up exercises and subsided after 10 minutes rest. It had gradually worsened and interrupted his dancing.

On examination, swelling of the medial aspects of both mid-feet was apparent. After strenuous activity these swellings became tender, tense and cyanosed. All symptoms, tenderness and cyanosis subsided after rest. Radiography and bone scans were normal, but MRI revealed hypertrophy of all the muscles of the medial and central compartments of both feet (Fig. 1).

Intracompartmental pressure was measured using a 20 " indwelling catheter in association with a small portable pressure monitor allowing for both single and continuous monitoring. Pressure was measured in the central and medial compartments of both feet. The measurements were performed initially at rest and a value of $10 \mathrm{mmHg}$ was recorded for each compartment with the patient supine. He was then asked to jump and run vigorously and on the appearance of pain, pressure measurements were again recorded with the patient supine. Values of $80 \mathrm{mmHg}$ in the central compartments and $35 \mathrm{mmHg}$ in the medial compartments were recorded. These gradually returned to the resting levels during a 30-minute rest period.

Bilateral decompressive fasciotomy was performed through a $5 \mathrm{~cm}$ incision along the medial aspect of the mid-foot just beneath the proximal half of the first metatarsal. This approach affords an easy exposure of the medial and central compartments (Fig. 2). Fasciotomy was performed by incising the medial extension of the plantar fascia and the intermuscular septum laterally, relieving both compartments. The patient began walking

F. Lokiec, MD, Resident

I. Siev-Ner, MD, Resident

M. Pritsch, MD, Chief of Staff

Department of Orthopaedic Surgery, Sheba Medical Centre, Tel Hashomer, Israel 52621 and the Israel Dance Medicine Centre, 22 Melchet Strett, Tel Aviv 65234, Israel.

Correspondence to Dr F. Lokiec.

(C) 1991 British Editorial Society of Bone and Joint Surgery 0301-620X/91/1 R01 \$2.00

J Bone Joint Surg [ Br] 1991 ; 73-B:178-9.

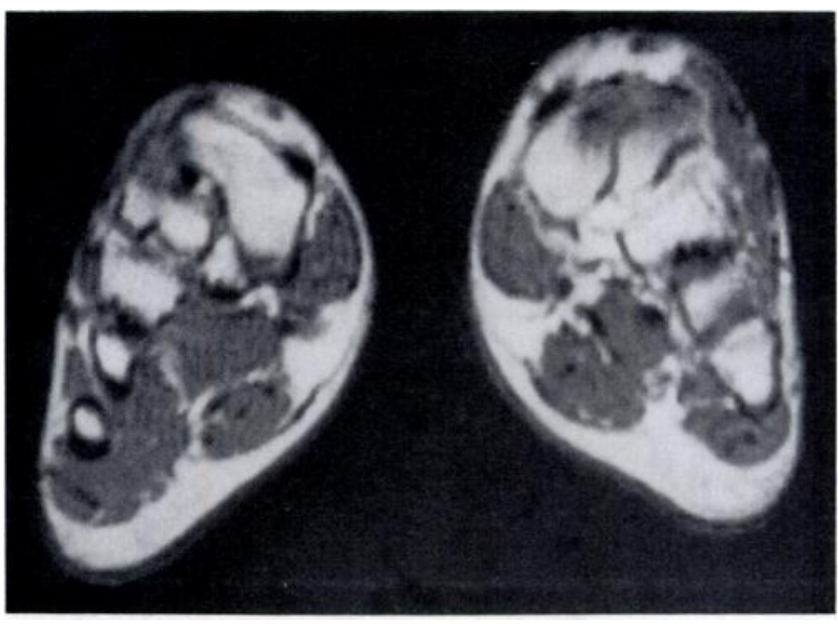

Fig. 1

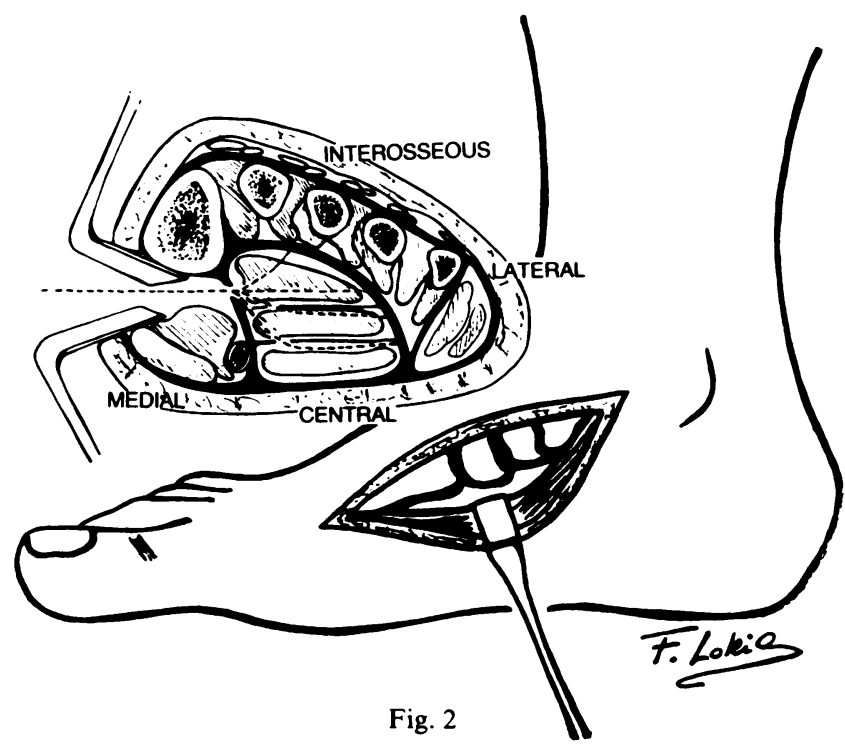

on the third postoperative day and returned to normal activities gradually. Full ballet activity was achieved eight weeks after surgery without symptoms.

Discussion. Although compartment syndromes of the foot have been reported, these have all been related to acute injury (Bonutti and Bell 1986; Myerson 1987; Starosta, Sacchetti and Sharkey 1988; Ziv et al 1989). In all cases decompressive fasciotomy gave relief of the symptoms. In our patient the condition was chronic, and diagnosis was made possible by the use of flexible slit catheters allowing intracompartmental pressures to be measured both at rest and during activity without disturbing the position of the catheter tips. 
As far as we know this is the first such case in the literature. However, we believe that chronic compartment syndrome of the foot is not a rare entity but rather an undiagnosed one. As foot complaints are common in athletes and dancers, chronic compartment syndrome should be considered in the differential diagnosis.

No benefits in any form have been received or will be received from a commercial party related directly or indirectly to the subject of this article.

\section{REFERENCES}

Bonutti PM, Bell GR. Compartment syndrome of the foot: a case report. J Bone Joint Surg [Am] 1986; 68-A :1449-51.

Myerson M. Acute compartment syndromes of the foot. Bull Hosp Jt Dis Orthop Inst 1987; 47:251-61.

Starosta D, Sacchetti AD, Sharkey P. Calcaneal fracture with compartment syndrome of the foot. Ann Emerg Med 1988; 17: 856-8.

Ziv I, Mosheiff R, Zeligowski A, Liebergal M, Lowe J, Segal D. Crush injuries of the foot with compartment syndrome: immediate onestage management. Foot Ankle 1989; 9:185-9.

\title{
A QUICK METHOD OF TAKING A BONE GRAFT
}

\author{
G. P. GRAHAM, C. M. DENT,
}

\author{
D. G. JONES
}

Cancellous bone grafts are commonly used in orthopaedic procedures. Unfortunately, taking a bone graft from the iliac crest is time consuming and not without complications. The bone which is harvested by traditional methods using a gouge or an osteotome is often in the form of large chips which may have to be cut into smaller pieces. This process is laborious and, as those who have been stabbed by the piece of bone they have been trying to cut will testify, not without hazard.

By using a powered acetabular reamer to harvest the graft, bone may be taken from the iliac crest in the form of reamings. The reamer is held against the outer table of the wing of the ilium so that the outer table and the

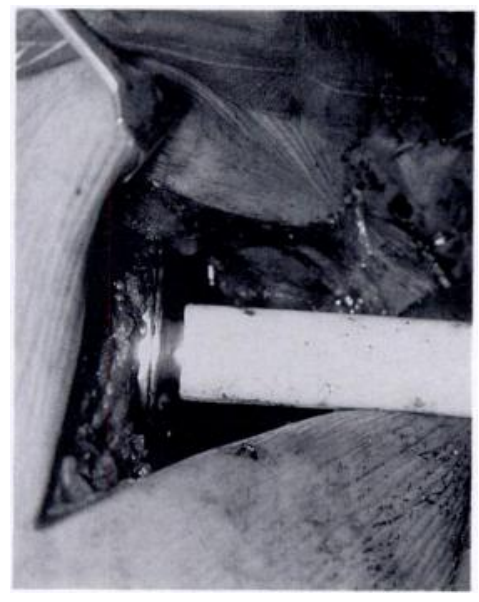

Fig. 1

G. P. Graham, FRCS, Senior Registrar

C. M. Dent, FRCS, Registrar

Department of Traumatic and Orthopaedic Surgery, Cardiff Royal Infirmary, Newport Road, Cardiff CF2 1SZ, Wales.

D. G. Jones, FRCS, Consultant

Fracture and Orthopaedic Unit, Royal Gwent Hospital, Cardiff Road, Newport NP9 2UB, Wales.

Correspondence to Mr G. P. Graham.

(C) 1991 British Editorial Society of Bone and Joint Surgery $0301-620 X / 91 / 1$ R99 $\$ 2.00$

J Bone Joint Surg [Br] 1991 ; 73-B:179.

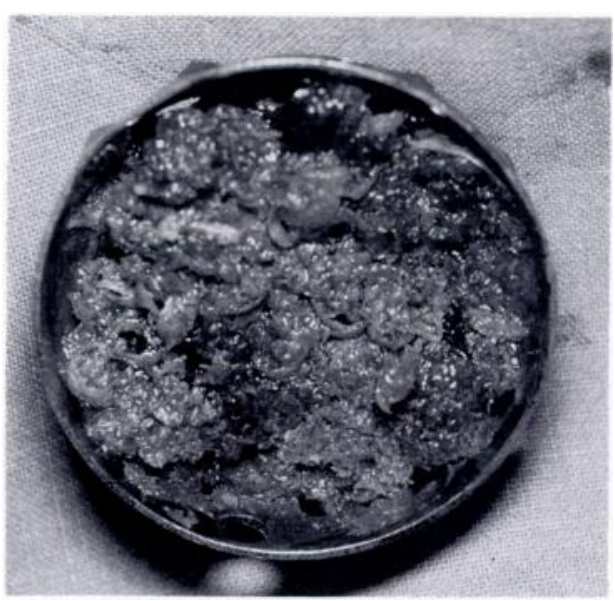

Fig. 2

cancellous bone beneath it are removed (Fig. 1). The inner table may be left undamaged. The shape of the reamers is ideal for removing cancellous bone from under the iliac crest while leaving the shell of the crest undamaged.

The bone obtained in this way is in the form of reamings (Fig. 2) with a very large surface area. It is of no use as structural graft, but may be used in place of cancellous bone chips. When the reamings are squeezed in a swab they dry to the form of a workable paste.

The main advantage of the method is the speed and safety with which a large amount of bone graft may be taken. Using the acetabular reamer is safer than using an osteotome or gouge, as the risk of penetrating the inner cortex or sacro-iliac joint is less. Moreover, the risk of splashing blood is less as no hammering is required, and, as there are no sharp pieces of bone the possibility of being cut by the graft is also less.

The method described has been found to be quick, easy and without complications.

No benefits in any form have been received or will be received from a commercial party related directly or indirectly to the subject of this article. 